\title{
FAZENDO E DESFAZENDO GÊNERO NA POLÍTICA: UMA HISTÓRIA DE VIIDA
}

\author{
HACIENDO Y DESHACIENDO GÉNERO EN LA POLITICA: \\ UNA HISTORIA DE VIDA
}

DOING AND UNDOING GENDER IN POLITICS: A LIFE STORY

\author{
Adller Moreira Chaves ${ }^{1}$ e Eloisio Moulin de Souza ${ }^{1}$ \\ ${ }^{1}$ Universidade Federal do Espírito Santo, Vitória/ES, Brasil
}

\begin{abstract}
RESUMO: Este artigo tem como objetivo analisar como o gênero é feito e desfeito dentro da política institucional. Para tanto, investigou-se a história de vida de uma vereadora, sendo que a produção dos dados foi feita por meio de 13 encontros. Nestes, ocorreram as entrevistas que permitiram entender a relação entre a história de vida da participante com o fazer e desfazer o gênero no contexto da política partidária institucional. Os dados produzidos foram analisados por meio de análise de discurso, onde constatou-se a importância e a influência da família, da escola e do trabalho na constituição das performances e performatividades de gênero no legislativo municipal. As histórias relatadas pela vereadora mostram que as relações de poder no contexto em que está inserida manifestam as performatividades e regulam suas possíveis performances no espaço legislativo. Dessa forma, constatou-se que o fazer masculinidade é utilizado pela participante como estratégia para a sua sobrevivência neste espaço.
\end{abstract}

PALAVRAS-CHAVE: Gênero; Política; Performance; Performatividade; Identidade.

RESUMEN: Este articulo tiene como objetivo analizar como género es hecho y deshecho dentro de la política institucional. Para tanto, el estudio se basó en las historias de vida de una concejal, con datos producidos a lo largo de 13 encuentros. En estos, ocurrieron las entrevistas que permitieron entender la relación entre la historia de la vida de la participante con el hacer y deshacer el género en el contexto de la política partidaria institucional. Los datos producidos fueron analizados por medio del análisis del discurso onde se ha constatado la importancia e influencia de la familia, de la escuela y del trabajo en la constitución de las performances y performatividades de género en el legislativo municipal. Las historias relatadas por la concejal muestran que las relaciones de poder en el contexto en que está inserida manifiestan las performatividades y regulan sus posibles performances en el espacio legislativo. Se constató que el hacer masculinidad es utilizado por la participante como estrategia para su supervivencia en este espacio.

PALABRAS CLAVE: Género; Política; Performance; Performatividad; Identidad.

ABSTRACT: This paper aims to investigate how gender is done and undone in politics. The life story of a councilwoman was analyzed and data were collected in 13 meetings. The interview was the main tool used in this study, given it allowed the researcher to understand the connection between the participant's life story and gender doing and undoing in the context of politics. The data analysis was carried out through discourse analysis and it was possible to verify the importance and influence of family, school and work on gender performances as well as performativity in the municipal legislative chamber. The stories narrated by the councilwoman show that power relations in such context reveal performativities and regulate their potential performances in the legislative context at the municipal level. Therefore, it was concluded that the participant resorts to simulating masculinity as a survival strategy in such environment.

KEYWORDS: Gender; Politics; Performance; Performativity; Identity. 


\section{Introdução}

$\mathrm{O}$ mundo passou por grandes transformações no século $\mathrm{XX}$, as quais desencadearam mudanças históricas, sociais e econômicas. Este fato alterou tradições e padrões culturais, influenciando o conceito social do que é ser mulher (Bruschini \& Puppin, 2004; Simões \& Hashimoto, 2012), despertando a comunidade acadêmica e científica para as discussões acerca das relações de gênero na sociedade. No Brasil, esta discussão começou tardiamente, e os estudos começaram a ter maior relevância no início da década de 90, período em que ocorreu um aumento no número de publicações sobre o tema. Na década seguinte houve um crescimento dos estudos das relações de gênero no Brasil, mas existe uma carência de pesquisas nesta área em espaços organizacionais/institucionais (Davel \& Alvadipani, 2003; Souza, Corvino, \& Lopes, 2013). Portanto, este artigo pretende ocupar esta lacuna ao buscar entender como gênero é feito e desfeito por uma vereadora dentro da Câmara Municipal em que está inserida.

Há uma necessidade de avançar no debate sobre as transformações ocorridas nas mulheres dentro de espaços organizacionais masculinizados. Neste sentido, essa pesquisa visa contribuir com o entendimento sobre a atuação das mulheres em espaços legislativos, considerando a importância deste espaço e do exercício da atividade legislativa na constituição da sua identidade de gênero. Entretanto, verifica-se a importância e conexão entre família, escola e trabalho no processo de fazer e desfazer gênero na política institucional legislativa. Portanto, gênero precisa ser problematizado e discutido em espaços organizacionais, pois a entrada das mulheres em diversos espaços em que anteriormente eram excluídas não só criou novos arranjos sociais relacionados ao gênero, mas também estratégias para atuação nestes espaços (Cramer, Paula, \& Silva, 2002). Sendo eleitas para uma Casa Legislativa, as mulheres são inseridas em um espaço marcado por fortes relações de poder, onde a construção de sua identidade de gênero é constantemente influenciada (Foucault, 1985). Assim, a inserção das mulheres na política partidária institucional requer atenção de pesquisadores interessados nos estudos de gênero, principalmente sobre a produção identitária de mulheres nestes contextos, possibilitando reflexões a respeito dos desafios vivenciados por elas no cotidiano das casas legislativas.

Este artigo está dividido em quatro seções além desta introdução. Primeiramente, discute conceitos sobre gênero de acordo com a abordagem pós-estruturalista, focando nos conceitos sobre fazer e desfazer gênero, performance e performatividade. Em seguida, são apresentados os aspectos metodológicos utilizados na pesquisa, demonstrando os caminhos percorridos para a produção e análise dos dados. Posteriormente, são realizadas as análises dos dados produzidos, discutindo o fazer e desfazer gênero na política institucional legislativa. Por fim, as considerações finais são apresentadas.

\section{Debatendo Gênero}

A té o século XVIII não existia a classificação de gêneros binária da forma como a conhecemos hoje. Homens e mulheres não eram vistos como opostos, mas a mulher era considerada um ser inferior entre o ser humano (Laqueur, 2001; Souza \& Carrieri, 2010). Neste período, ocorreu o Iluminismo, onde foram propostos alguns ideais, destacando: a valorização da individualidade dos sujeitos e o advento do capitalismo. Por conta disso, 
houve a necessidade do aprofundamento da diferenciação das identidades sociais para cada indivíduo desempenhar, destinando ao homem o espaço público e à mulher o espaço privado (Prasad, 2012; Souza \& Carrieri, 2010). Nos séculos XIX e XX as mulheres lutaram buscando novos espaços sociais, abrindo o caminho para a discussão feminista na academia e na sociedade.

Beauvoir (2014) contribuiu profundamente com esta discussão ao tratar o gênero como um traço cultural e o sexo como biológico. Para ela, as características físicas são determinantes para a mulher biológica, mas o que é ser mulher na sociedade é influenciado pelas relações sociais em tempos e locais específicos. Isso define as atribuições, funções e espaços que elas podem ocupar. Homem e mulher são definições biológicas, já masculino e feminino são traços culturais (Beauvoir, 2014). Apesar de sofrer algumas críticas, esta ideia passou a ser amplamente aceita e difundida na década de 60 nas universidades ocidentais, entretanto, ainda permanecia uma grande confusão na sociedade em relação aos termos, pois, para o senso comum, gênero era visto também como sendo aspectos físicos, biológicos e anatômicos.

O conceito de gênero até aquele momento era limitado, impedindo a ampliação do seu significado, bem como sua problematização (Louro, 2003). Scott (1995) e outras pesquisadoras feministas (Butler, 2003; Louro, 2003) visavam dar ênfase nas distinções que se baseavam no sexo como fundamentalmente social. Assim, o conceito de gênero deve considerar todo um sistema de relações, inclusive o sexo, mas que o gênero não é diretamente determinado pelo sexo, e vice versa, bem como gênero não determina a sexualidade (Butler, 2003; Louro, 2003; Scott, 1995). Butler (2003) afirma que ao nascer e ser incluído em uma das categorias de gênero, cada indivíduo será educado e compelido a seguir certos padrões performáticos da sua categorização, sendo levado pelas relações de poder que o cerca a se encaixar nas categorias dicotômicas e binárias que circulam pelos discursos: homem e mulher, feminino e masculino, hétero e homo. Assim, diversas pesquisas iniciaram a discussão sobre a oposição entre essas categorias dicotômicas, bem como problematizaram a existência da oposição entre elas, destacando-se nesse debate a abordagem pós-estruturalista.

Gênero no pós-estruturalismo afasta da centralidade biológica determinista e da lógica binária: masculino versus feminino. Os pós-estruturalistas criticam esta produção binária afirmando que é uma redução simplista, pois a construção de todas as identidades, inclusive masculinas e femininas, são provisórias, heterogêneas, não essenciais e múltiplas, apresentando fragmentações, sempre se movimentando e estando sujeita a constantes transformações (Louro, 2003). Butler (2003) desconstruiu o conceito de gênero que permeou grande parte da discussão da teoria feminista desde a década de 60. Ela critica o binarismo entre gênero e sexo, pelo qual gênero seria culturalmente construído e sexo algo biologicamente natural. Para a autora tanto gênero e sexo são culturalmente construídos pelos discursos e devem ser desnaturalizados (Butler, 2003). Assim, "gênero é a estilização repetida no corpo, um conjunto de atos repetidos no interior de uma estrutura reguladora altamente rígida" (Butler, 2003, p. 59). Gênero é um instrumento expresso pelos discursos e pela cultura visando a legitimação da ordem, em que o sexo está inscrito nele, mas ele não é a "interpretação cultural do sexo" (Butler, 2003, p. 25). Para a autora, gênero produz uma falsa ideia de estabilidade, onde a heterossexualidade estaria assegurada pelo binarismo entre dois sexos opostos. 
O pós-estruturalismo considera que tanto gênero quanto o sexo são performativos, diferentes e com as mais variadas formas. A categorização binária em homem e mulher é limitada, pois as identidades são fluidas e sem repetições ou padrões (Butler, 2003). As categorizações binárias, como homem e mulher ou masculino e feminino, são vistas pelo pós-estruturalismo como ambíguas, imprecisas, transitórias e sempre contingenciadas por um contexto social, cultural, econômico e político (Scott, 1995). Ademais, os estudos pós-estruturalistas se concentram na fragilidade das construções sociais, em que está inserido gênero, demonstrando que ele é dinâmico e mutável, apenas performances temporárias (Alvesson \& Billing, 2009). Por fim, os pós-estruturalistas acreditam que a função do feminismo é ressignificar identidades de gênero através da desconstrução de categorias universais e essenciais, tal como homem e mulher, mostrando que a naturalidade biológica com que é tratado esse assunto é uma estratégia da matriz heterossexual para mascarar o conteúdo político e as relações de poder que envolvem a construção das identidades de gênero (Butler, 2003).

Gênero é performativo e não há uma identidade de gênero por trás das expressões de gênero, mas a identidade é construída performativamente pelas expressões que acredita ser resultado (Butler, 1999, 2003). As normas são naturalizadas através de processos de repetições contínuas, fazendo com que as pessoas exerçam performances. Nessas repetições das normas discursivas que as práticas de subjetivação são construídas e legitimadas, e através dasperformatividades, as normas binárias dos gêneros são estabelecidas e reiteradas. Por isso, gênero não é algo que os indivíduos possuem, mas fazem e desfazem (Butler, 1999, 2003).

\section{Fazendo e desfazendo gênero}

A discussão sobre gênero mostra que não é universal ou que possui uma essência, mas algo que faz e desfaz, fluído e fragmentado. Mas, o que vem a ser esse fazer e desfazer gênero? Gênero é uma das principais formas de se organizar a vida em sociedade, desde atividades sociais e até as interações, fazendo com que as pessoas sofram pressões para que se comportem de determinadas maneiras (West \& Zimmerman, 1987). As atividades laborais desempenhadas na sociedade em que as performances estão previamente condicionadas são exemplos, assim os indivíduos são compelidos por causa de características anatômicas a agir de determinado modo, influenciando toda forma de organização da vida na sociedade atual (West \& Zimmerman, 1987).

West e Zimmerman (1987) discutem que para os indivíduos se tornarem sujeitos eles são compelidos a fazerem e desfazem gênero. Este é um processo social constantemente negociado, não algo inato presente em homens ou mulheres. Dessa forma "os participantes na interação organizam suas múltiplas atividades para refletir ou expressar gênero, onde estão dispostos a perceber o comportamento dos outros de forma semelhante” (West \& Zimmerman, 1987, p. 4, tradução própria). Todos os indivíduos que convivem em sociedade são pressionados e compelidos para cumprirem determinadas expectativas de gênero, estabelecendo hierarquias sociais em que homens ocupam o topo desta hierarquia e as mulheres são tratadas como o outro (Machado, 1998; Schilt \& Connell, 2007).

Fazer e desfazer gênero está relacionado com a gestão de situações sociais, e existem formas de se comportar consideradas adequadas para cada categoria. Além disso, práticas discursivas sociais categorizam os indivíduos como membros de determinado gênero 
(Thanem \& Wallenberg, 2014). Mesmo assim, os indivíduos vivem rompendo seguidamente com as normas dominantes de masculinidade e feminilidade, sempre fazendo e desfazendo gênero, dialogando com os contextos sociais em que estão inseridos (West \& Zimmerman, 1987). Fazer gênero compreende diversas práticas de pressão, coibição e discriminatórias, estabelecendo que os homens e as mulheres tratem o outro de forma desigual pelo fato deles possuírem características anatômicas diferentes. O fazer gênero não deve ser visto apenas como uma prática social, mas como uma ação coercitiva para organização da sociedade (Czarniawska, 2006). Diversos pensadores sobre gênero enfatizam que os processos sociais produzem gênero de uma pessoa e não a anatomia biológica (Westbrook \& Schilt, 2014). West e Zimmerman (1987) estabelecem gênero como um comportamento imposto, em que a discriminação é um elemento significativo na atribuição do fazer gênero, uma maneira coercitiva para gerar uma legitimidade em uma organização social baseada em identidades de gênero.

Segundo Westbrook e Schilt (2014), no ambiente institucional, as características visíveis dos indivíduos são muito importantes para as interações, fazendo com que os próprios colegas de trabalho esperem certas maneiras de agir pelo que eles julgam serem adequados ao gênero ao qual o colega pertence. Isso faz com que as identidades das mulheres sejam feitas e desfeitas por pressões institucionais e da sociedade e que, por isso, sejam vistas como identidades falhas e estereotipadas. Muitos estudos demonstram que as mulheres, ao adentrarem em ambientes masculinizados, para que sejam aceitas, desvalorizam a própria feminilidade (Charles, 2014; Thanen \& Wallenberg, 2014). Charles (2014) observa que as mulheres que se inserem em posições ocupadas em sua maioria por homens, como na política, fazem masculinidade para que sejam legitimadas. A autora ainda diz que há uma dificuldade em alterar a cultura da organização apenas fazendo e desfazendo gênero de maneira diferente do dominante em nível individual, em que apenas grupos poderão alterar a ordem normativa, e normalmente os grupos apenas reiteram as normas performativas (Charles, 2014). Estudos sobre a mulher na política demonstram que elas não têm ocupado posições deliberativas mesmo fazendo masculinidade, e os partidos não dão espaços para elas. Diversos partidos excluem a mulher de suas discussões, principalmente os considerados de direita (Araújo, 2005; Wright, Azevedo, \& Santana, 2012).

Louro (2003), ao estabelecer uma conexão entre as relações de gênero e as relações de poder, diz que as relações de gênero são construídas na e pelas relações de poder, e ambas são constituídas simultaneamente (Scott, 1995). Butler $(1988,1999)$ afirma que o fazer e desfazer gênero ou a construção do gênero são formações discursivas que circundam os indivíduos. Butler $(1999,2003)$ trata gênero como algo performativo, em que não existe uma identidade de gênero por trás das expressões de gênero, mas a identidade é construída performativamente pelas "expressões" que acredita ser o seu resultado. Indivíduos são construídos por atos normativamente repetitivos, mas que não são determinantes, podendo inclusive reconstruir simultaneamente a ordem social estabelecida. Assim, as normas são naturalizadas através de processos de repetições contínuas, fazendo com que as pessoas performem gênero. Através das performances masculinidade ou feminilidade, as normas binárias dos gêneros são estabelecidas e reiteradas. (Butler, 1999, 2003). Portanto, diante do exposto, faz-se necessário entender melhor os conceitos de performance e performatividade e suas relações com a produção de gênero. 


\section{Perfomance e performatividade}

Durante a discussão sobre gênero, muito foi dito sobre performances e performatividades, e essa seção busca analisar seus conceitos. A performatividade é a reiteração de normas discursivas a serem seguidas por determinada identidade de gênero, ou seja, quais são as performances a serem seguidas por certos indivíduos que possuem determinadas características (Butler, 1988). "A performatividade deve ser compreendida não como um ato singular ou deliberado, mas, ao invés disso, como a prática reiterativa e citacional $^{1}$ pela qual o discurso produz os efeitos que ele nomeia” (Butler, 1999, p. 111). Butler (1999, 2003) afirma que gênero deve ser entendido como uma expressão performativa, não algo que é previamente dado ou inato em determinados indivíduos. Assim, performance é a prática do indivíduo que a performatividade coage-o e o compele a fazer por meio de normas discursivas. Estas normas apresentam em si a possibilidade de resistência, ou seja, trazem as possibilidades de subversão das normas discursivas, demonstrando que estas normas não são determinísticas (Butler; 1999, 2003; Phillips \& Knowles, 2012).

As ações dos indivíduos são compelidas a performarem estas normas para se tornarem aceitas socialmente e se tornarem sujeitos, Sendo assim, atos performativos são repetições de atos anteriores, em que se busca uma repetição citacional de forma que os indivíduos são levados a não se identificar com os gêneros através de um ato único, mas de uma repetição normatizada de atos (Lloyd, 1999).

Indivíduos, ao performarem suas identidades de forma diferente daquelas que a performatividade os compele a fazerem, podem alterar as normas. Essas performances subversivas geralmente desafiam o modelo binário produzido pela matriz heterossexual e são coibidas socialmente. Muitas vezes, a subversão é coibida porque pode alterar as normas vigentes e consequente a performatividade, fazendo com que seja possível existir com outras formas identitárias (Butler, 1999, 2003). Butler (1999) discute que as performances nos espaços são feitas com objetivos estratégicos em relação ao enquadramento da performatividade dominante, mas que este objetivo não é próprio do sujeito, e sim uma relação de poder estratégica para a consolidação dessa performatividade. Segundo Butler (1999), é importante esclarecer que, nas discussões sobre performatividade e performances, não existe uma associação para que o indivíduo represente gênero de forma voluntarista. A autora disserta que a performatividade é repetida pelas normas que vêm antes do agente, ou seja, as normas que regulam a questão do sexo reproduzem práticas já reguladas. Dessa forma, observa-se que gênero não é uma escolha do indivíduo, mas sim uma produção normativa que envolve relações de poder (Butler, 1999).

\section{Caminhos percorridos}

Esse trabalho é um estudo empírico qualitativo que buscou analisar como uma vereadora do interior da Bahia faz e desfaz gênero dentro da Casa Legislativa na qual está inserida, ressaltando que a participante está em seu terceiro mandato. Para a escolha da participante, foram estabelecidos três critérios: (a) ter exercido mais de um mandato eletivo no cargo de vereadora; (b) ter atuado pelo menos seis anos em cargo eletivo; (c) ter um histórico de luta para espaço de atuação de mulheres na política. 
Para a produção de dados utilizou-se do método biográfico. Esta abordagem biográfica consiste em narrar histórias e observar através delas o sujeito em suas práticas e negociações sociais que lhe são particulares, construindo sua cosmovisão (Barros \& Lopes, 2014). Na história de vida, a informante tenta reconstruir os acontecimentos que viveu em um determinado tempo, fazendo com que a abordagem do pesquisador, ao colher o relato, seja fundamental na condução de todo o processo (Queiroz, 1988). O método escolhido destacou dois aspectos: os fatores que constituíram as histórias de vida da participante e o elo entre a história individual narrada e a história coletiva (Barros \& Lopes, 2014).

Trabalhar com as histórias de vidas é uma experiência muito valiosa, pois através dela pode se entender muito sobre as práticas sociais e a vida em sociedade dos indivíduos, observando como se dão as relações sociais que constroem o seu mundo e que também são construídas por eles (Barros \& Lopes, 2014). A história de vida contribui de forma única para as pesquisas, pois ela pode dar sentido em processos que antes eram pouco explorados, como aspectos identitários (Becker, 1999).

Ocorreram 13 encontros para recolhimento da história de vida, mas apenas 11 foram gravados, com duração média de 40 minutos. Os encontros gravados foram feitos no gabinete da participante, onde estavam presentes apenas o pesquisador e ela. Esses encontros geraram 13 diários de campo, que foram elaborados no mesmo dia, onde o pesquisador escreveu particularidades desses momentos. As transcrições foram feitas pelo próprio pesquisador e, em sua maioria, entre um encontro e outro. Elas foram transcritas com auxílio do software Express ScribeTranscription, para facilitar e otimizar o tempo de transcrição. As transcrições resultaram em aproximadamente 100 laudas, com a fonte Arial, corpo 12.

Para o tratamento dos dados, foi escolhida a Análise de Discurso (AD). Segundo Gill (2002), existem pelo menos 57 formas de análises de discurso que partilham a rejeição sobre a linguagem como um meio neutro de reflexão ou descrição do mundo que cerca cada um, mas ela é uma ferramenta fundamental para a construção social. A AD busca a compreensão do mundo social para os sujeitos pesquisados, explorando como a linguagem o constrói (Souza \& Carrieri, 2014). Dentro das inúmeras AD, este estudo buscou adentrar na tradição pós-estruturalista, onde, em conjunto com o referencial teórico, rompe com a visão realista da linguagem e rejeita a noção de sujeito livre, unificado e coerente, buscando considerar não só as informações textuais, mas a constituição das relações pesquisadas no ambiente estudado, onde "está interessado não nos detalhes dos textos falados e escritos, mas em olhar historicamente os discursos” (Gill, 2002, p. 246). Segundo Nogueira (2001), esta é uma abordagem que se enquadra na Análise Crítica do Discurso, em que há uma busca por padronização em contextos amplos na sociedade. A preocupação ao analisar dessa forma é a busca pelas relações de saber e poder.

O pós-estruturalismo dá uma liberdade ao analisar os dados produzidos, afirmando que o discurso não se limita e não significa fala, mas é algo que perpassa as relações da sociedade. Não analisa somente o dito, mas também o não dito. No segundo, se enquadra o vestuário e diversos outros aspectos que foram também observados na pesquisa (Foucault, 1985). Foucault (1999) afirma que o discurso tem uma finitude e é um acontecimento histórico, mas que não possui uma estrutura. O discurso é o que dá coesão às vidas em sociedade e à história individual e, através dele, manifesta a realidade e materialidade do mundo. O discurso é um instrumento de luta, moldado pelas relações de poder que dirigem as ações dos sujeitos. Dessa forma, os discursos serão analisados nesse trabalho à luz do referencial teórico, o qual já elucida muito sobre os discursos e as relações de poder inclusas neles. 


\section{Fazendo e desfazendo gênero na política}

Maria $^{2}$ afirma que desde muito nova foi "envolvida na política". Sua mãe a levava para os comícios e estava em contato com os partidos políticos desde que era criança. A participante revelou que sua mãe a colocava para subir nos palanques e "cantar músicas, jingles políticos na frente de todo mundo" (Maria). "Ela achava tudo isso normal, então eu vivi nesse ambiente político" (Maria). Dos quatro irmãos, apenas Maria e o mais novo que eram ligados, e são até hoje, à política, os outros dois nunca gostaram. "A gente ia, a gente participava, a gente cantava em palanque" (Maria). Assim foi o período da infância e adolescência de Maria na política. Após encerrar o ensino médio, ela saiu de casa para estudar em Salvador, no período em que ocorreu a eleição para presidente do Brasil, em 1989. Maria relata que defendeu a candidatura de Mário Covas, que fazia parte dos "tucanos". Ela foi para o diretório do PSDB, pegou o plano de governo, estudou e procurou saber, "na faculdade, a gente tinha disciplinas de debate, coisas assim, aí dividia e eu sempre ficava com Mário Covas, nunca com outro" (Maria). No dia da eleição, Maria relatou que, apesar de não conhecer quase ninguém em Salvador, colocou adesivo e foi para boca de urna, acreditando que assim estava fazendo seu papel como eleitora e cidadã.

Pertencente ao Diretório Central dos Estudantes (DCE), Maria afirma que esse fato não a influenciou diretamente, pois o "povo era aqueles extremistas, [...] era muito esquerda, [...] iam pra reitoria, fechava... e eu não, eu era Mário Covas”. Os discursos de Maria demonstram que ela já possuía uma consciência política no que acreditava, mesmo em um ambiente de esquerda na UFBA, ela não gostava nem de um extremo e nem do outro, "então eu sempre fui mais centro-esquerda na época, o PSDB era na época centro-esquerda, né?!” (Maria).

Com 17 anos de idade, Maria começou a trabalhar em hospitais da Capital como estagiária, tendo que se impor como profissional e como mulher. Naquele tempo, "enfermeira era considerada merenda de médico” (Maria), e a participante enfrentou essa situação. Além disso, ela liderou equipes de técnicas de enfermagem muito mais experientes, usando o saber como uma forma de gerar subordinação (Foucault, 1985, 1995). Saindo da faculdade, estava empregada na terapia intensiva de um hospital em Salvador. Depois de um período trabalhando naquela cidade, ela foi acometida por uma enfermidade, sendo aconselhada a voltar a morar no interior. Entre alguns trabalhos próximos da sua cidade natal, Maria se torna sócia de um hospital pediátrico, para conseguir capital para ter seu próprio hospital. Depois de buscar a implementação em cidades da região, a mãe de Maria, que havia se tornado vereadora na cidade natal, viabilizou a construção do hospital, onde ela atuou na direção após o divórcio com o sócio e marido.

Antes de ser vereadora, Maria foi diretora do hospital e, segundo ela, enfrentou "as maiores dificuldades de minha vida, pois eles achavam que eu, enfermeira e mulher, não poderia ser dona do hospital". Durante este tempo, até as mulheres viam a identidade de Maria como falha para aquela posição. Na direção do hospital, Maria se consolidou como uma figura conhecida em sua cidade natal, ajudando na conquista da sua primeira eleição para a Câmara Municipal, em 2008. 


\section{Entrando na politica institucional}

Antes de Maria ser candidata, sua mãe já havia sido vereadora por dois mandatos. Ela "candidatou 2 vezes sozinha praticamente, pra poder se eleger" (Maria). Assim, os discursos de Maria evidenciam que no ambiente familiar foi sua mãe "que quebrou os paradigmas dentro da família”.

Eu lembro que na primeira eleição ela se candidatou mesmo com meu pai criticando, a gente ouvia muito assim: 'isso né coisa pra poder mulher casada tá procurando, isso né coisa pra pessoa tá se envolvendo, política não é coisa pra uma pessoa como você’. […] minha mãe quebrou mais essa coisa, então quando foi colocado meu nome, a família já estava adaptada teoricamente a processos políticos, meu pai, no $2^{\circ}$ mandato de minha mãe, recuou mais... por motivos pessoais dele, mas meu irmão sempre manteve o dia-a-dia, acompanhar ela aqui na Câmara né?! (Maria)

Sobre a entrada na política da mãe de Maria, os discursos evidenciaram que ela sofreu muita discriminação, pois aquele não era espaço considerado para uma mulher. É importante abordar que, nesse período histórico, o trabalho da mulher era visto apenas como uma extensão das atividades domésticas (Bruschini \& Puppin, 2004). O pai de Maria não acreditava que a política era um ambiente para sua esposa, e seus discursos expressaram o descontentamento com tal atitude. Apesar disso, no final, acabou apoiando-a depois de muita relutância. A performance expressa pelos discursos dele está vinculada com a reprodução de práticas inscritas na sociedade em que estavam inseridos, onde a política não era local de mulher, muito menos mulher casada. Estes discursos são normativos e vinculados às normas regulatórias do gênero e do sexo em que a fala do homem manifesta um gesto de posse sobre mulher dentro do casamento, normas performativamente repetidas. Os discursos do pai de Maria e sua atuação o identificava com normas regulatórias naquele tempo e espaço (Butler, 1999, 2003).

A mãe de Maria se elegeu e se reelegeu, mas em seu segundo mandato foi acometida por alguns problemas de saúde. Assim, faltando dois anos para encerrá-lo, "a família decidiu que teria outro candidato, que a família ia apresentar pra dar essa continuidade e que seria eu Porque eu gostava, eu me identificava, aceitei” (Maria). É importante dizer que a participante vai de encontro ao que a bibliografia fala sobre a maioria das mulheres que conta com influência familiar na entrada na política, pois na grande maioria se deve ao marido ou pai, mas no caso de Maria foi a mãe, uma mulher (Barbosa, 2008).

Os paradigmas familiares e naquela Câmara de Vereadores já estavam sendo quebrados por sua mãe, que venceu muitas barreiras durante os 8 anos na vereança. Então, Maria se filiou no partido que a sua mãe foi eleita por duas vezes, onde ela seria a sucessora do espaço da mãe, que abriria a vaga para ela. Apesar disso, o pessoal do partido não considerava Maria uma candidata com potencial e iria apenas cobrir o coeficiente exigido pela legislação eleitoral de mulheres candidatas, falavam: "não, ela não ganha, quem é [Maria] que voltou agora de Salvador, passou 13 anos fora, ela não ganha” (Maria). Mas para a surpresa de todos, ela foi eleita com mais de 2.500 votos na primeira candidatura, em 2008 , um recorde na cidade e na região, até hoje não igualado. 
Depois de sua eleição, Maria buscou diferenciar o seu mandato da mãe, pois ela, em muitos momentos foi considerada despreparada e sem conhecimento para as discussões. É importante afirmar que o saber é uma ferramenta importante para relações de poder, inclusive, gerando subordinação. Em seus discursos, Maria evocava a importância do saber da legislação, das normas da Câmara e até como enfermeira para a sua atuação muitas vezes, dando-lhe reconhecimento (Foucault, 1985, 1995). Com a sua eleição como vereadora, acreditava que as coisas mudariam, e que faria realmente a diferença naquele local. Apesar disso, sua atuação mostrou que a sua atuação como mulher não foi nada fácil.

\section{Discursos na vereança}

Através dos discursos, Maria demonstra que buscava fazer sua obrigação como vereadora, mas foi visto que muitos colegas e parte da população não a via dessa forma. Maria diz que "criou uma identidade política dentro dos colegas" de que era uma vereadora séria e apresentava conhecimento para estar ali, mas isso não refletiu na sociedade, e sua reeleição ficou ameaçada por conta de que a população não assimilou este discurso. Em todos os encontros, ela manifestava a importância do saber para exercer poder dentro da sua atuação como vereadora, considerando que devia possuir ainda mais por ser mulher e enfrentar barreiras impostas pela sociedade. Quando adentrou na Casa Legislativa, Maria alterou o seu comportamento, sendo que até seus colegas de seu trabalho anterior em um banco de sangue comentaram que "nem parecia ela que atuava na Câmara” (Maria).

Assim, de ter um comportamento mais enfático né, ai tanto que... que... eu acho assim que são situações que a gente, é igual aquela coisa da natureza, ou você mata ou você morre, né?! Ou você muda o seu comportamento pra poder se impor também, ou então você vai ser, eu digo, igual a violência doméstica, quando a mulher aceita o primeiro tapa e não diz nada, então ela se submete aquilo ali, é igual a política, se na política você se acovarda na primeira intimidação ai eles sabem, 'oh aquela ali é fraquinha', é frágil, isso daí é fragilizada, [...], como eu fui sempre uma vereadora muito incisiva, muito assim de cobrança, muito discurso forte, então tentaram vê um ponto fraco pra poder justamente tentar me fragilizar, mas é nesse momento que ou a gente dá a volta por cima e não aceita ou então se a gente subjugar isso ai agora já era, a gente vai ficar sempre fragilizada nisso daí, né. [...] então, ou a gente se impõe, as vezes até no grito, ou até na coisa mais incisiva ou então a gente é jogada a... ao... diríamos... o escanteio, e vai ser mais um dentro só do plenário. Então, como meu temperamento era tímida mas eu sempre fui assim, decisiva, de ter opinião, de lutar por aquilo ali, então eu tenho um temperamento forte, né, então eu digo isso assim e tal e acabou. Mas assim, quando eu tenho meu direito sendo usurpado, sendo agredido eu também vou... é... pra fora pra poder lutar, porque se a gente recua, ai toma o espaço da gente. (Maria)

Dessa forma, Maria mudou o seu modus operandi completamente, alterando seus discursos ao adentrar na Câmara de Vereadores. É importante afirmar que ela mudou seu modo de agir, de falar, de se vestir e até as suas relações sociais. Charles (2014) afirma que para a mulher ter sobrevivência no ambiente político legislativo ela deve fazer masculinidades, pois a feminilidade não é vista como pertencente àquele espaço. Assim, foi visto 
nos discursos de Maria um fazer masculinidade para que fosse aceita e respeitada naquela casa legislativa. A performance de gênero que ela faz na Câmara surpreendia quem estava a sua volta, a ponto de afirmarem que não estavam reconhecendo-a. As identidades de gênero não são possuídas pelos indivíduos, são performances frágeis e mutáveis que, no caso de Maria, apenas reproduzia as performances que achava adequada para aquele momento e espaço (Butler, 2003). Dentro da Câmara Municipal, Maria rompeu seguidamente as normas dominantes, fazendo e desfazendo gênero. Apesar da performatividade repetir suas normas, Maria as subvertia ao fazer masculinidade no mesmo tempo que reforçava aquele ambiente como sendo um espaço exclusivamente masculino (Butler, 2003; West \& Zimmerman, 1987).

Em muitos encontros, Maria afirmava achar o ambiente da Câmara tranquilo para as mulheres, mas seus discursos afirmavam o contrário. Um exemplo era que ela sempre vai para as sessões acompanhada por uma figura de um homem, pois "quando a pessoa que está debatendo não tem argumento político, ele passa para o argumento da fragilidade da mulher" (Maria). Destarte, todas as sessões da Câmara ela vai acompanhada por seu irmão ou assessor. "Eu não venho com uma assessora, ou eu venho com um assessor ou eu venho com meu irmão” (Maria), fazendo isso para poder mostrar que não está sozinha e para coibir alguns comentários ou "até, talvez, um possível embate físico” (Maria). Este discurso é bem marcante, demonstrando que o ambiente da política institucional não é visto como pertencente à identidade considerada Outra, ou seja, a mulher e a performance da feminilidade (Machado, 1998).

Através dos discursos de Maria, observou-se que ela teve que performar masculinidades para ser aceita e tentar diminuir as discriminações de gênero dentro daquele espaço. Estes discursos demonstravam que a participante, sabendo dos problemas que como mulher enfrentaria naquele espaço, constrói estratégias para permanecer e ser atingida o mínimo possível. Em posições legislativas, onde historicamente predomina os homens, esta é uma atitude comum para a maioria das mulheres que se inserem neste ambiente (Charles, 2014). Os discursos do próprio local demonstram que aquele não é um espaço feminino ou para mulheres, inclusive em questões consideradas simples, como as vestimentas. A legislação não contempla a atuação mulher em praticamente nada dentro de casas legislativas. Como, exemplo, a Lei Orgânica da Câmara em que Maria atua trata das vestes do homem e não traz nada da vestimenta da mulher, exatamente por não considerar este espaço uma posição social para mulheres.

Então, na lei orgânica diz que o homem tem que vir na sessão portando com o blazer e gravata, né, e ainda tem que ter gravata, uma roupa formal realmente. A mulher não tem nada tratando, nenhuma abordagem sobre a vestimenta da mulher, ai que dá pra entender que as próprias leis não incluem a mulher dentro do poder legislativo, porque não traz uma abordagem sobre isso. Mas como a gente tem um respeito, né, com a casa legislativa, a gente sempre tem vindo se portado dentro da parte de vestimenta com uma roupa também formal nas sessões, sem usar roupas de alça e que exponha, mais uma roupa decente e que seja condizente com... com a roupa dos homens e de sessões formais, como a gente se procede na vida, no normal. [...]. Não tem nada. Nem lei orgânica, nem lei, nem o regimento interno, nada que privilegie a mulher. $\mathrm{O}$ único exemplo que tem é que quando o regimento interno fala da primeira sessão, na abertura dos trabalhos legislativos, onde ainda não tem presidente de Câmara, ele diz que quem tem que presidir a 
sessão é o vereador mais velho, pra poder depois se proceder a eleição da mesa diretora da câmara. Então, hora nenhuma tem nenhuma lei, nenhum artigo que trata nem de exclusividade e nem de benefício e nem de destaque até, né, para o trabalho legislativo da mulher na Câmara Municipal. (Maria)

A performatividade busca exercer o controle nos indivíduos pertencentes à Câmara Municipal Legislativa, onde se utiliza de instrumentos administrativos e jurídicos para este controle (Butler, 2003). Apesar disso, até neste aspecto, a mulher é excluída, não tendo nenhuma legislação que gere a sua forma de vestir. Todavia, os discursos de Maria evidenciaram que as relações de poder citacionais que atuam naquele local fazem com que ela também sofra pressões para se vestir de maneira adequada. Ainda que não tenha uma legislação específica para as mulheres, existem regras discursivas que são repetidas e circulam o tempo todo, uma performatividade para quais as roupas deveriam ser usadas por Maria (Butler, 2003).

Maria relata que dentro da Câmara a relação dela com os funcionários ou com a imprensa não é diferente de nenhum outro vereador. Todavia, ela afirmou que em nenhum momento eles valorizam-na como uma mulher naquele ambiente. Agora, se tratando dos partidos e grupos políticos, ela discursa com grande descontentamento e distanciamento, o que será tratado no último ponto dessa seção. Ainda discutindo sua atuação como vereadora, Maria fez diversas investigações sobre o dinheiro público e descobriu fatos que a levaram montar uma Comissão Parlamentar de Inquérito contra o prefeito.

\section{Discursos em uma CPI}

Uma CPI é quando o poder legislativo, seja ele municipal, estadual ou federal, conduz investigações, fazendo com que na própria Casa Legislativa sejam recolhidos os depoimentos e as informações a respeito do tema que está sendo investigado. Para sua instauração, devem ter algumas particularidades, variando em cada Casa Legislativa (Bulos, 2001). Na Câmara em que Maria estava inserida, eram necessárias 5 assinaturas de vereadores e “com muito esforço" (Maria), conseguiu-as.

Maria contou que essa CPI, a qual presidiu, foi a primeira dentro daquela Câmara contra um ato do chefe do executivo, algo que até aquele momento ninguém havia tido coragem de enfrentar. Ela visitou diversos órgãos fiscalizadores e, apesar de muitas ameaças e oferecimento de vantagens, relatou que não fez "o que seria incompatível com que acreditava ser correto, fechar os olhos e achar que não aconteceu” (Maria). Assim, ocorreu a abertura desta CPI e provou ser um desafio grande para Maria.

Eu acho assim, como falei com você, a CPI pra mim foi um desafio muito grande, foi a primeira Comissão Parlamentar de Inquérito julgando um ato do prefeito, que até então só tinha tido uma única CPI aqui dentro da Câmara de toda a existência dela, foi pra apurar um ato de atendimento de saúde no [Nome do Hospital], feito pelo vereador [Nome do Vereador], então... foi dificílimo, primeiro porque eu era mulher, né, então os próprios colegas não acreditavam, num creditavam, não dava credibilidade nisso daí. (Maria) 
Os discursos em relação a Maria demonstravam que existia uma visão da feminilidade como sendo algo inferior, e isso já faria com que ela não teria credibilidade para presidir a CPI. Ouvindo áudios do processo e entrevistas, foi observado que em todo o processo Maria performava o masculino visando "marcar território" (Maria), ou seja, sua posição na ordem do discurso, e, inclusive, em diversos momentos ela teve que discursar de forma agressiva e com violência. Portanto, ao manifestar a performances consideradas masculinas no momento em que presidia a CPI, ela subverteu as normas regulatórias de gênero, mas ao mesmo tempo ela as reiterou, pois o masculino tornava-se socialmente aceito como sendo gênero apropriado para aquele ambiente (Butler, 1999, 2003). Maria é compelida a fazer tanto o feminino quanto o masculino, ou seja, a performance não tem relação direta com o corpo biológico e nem é um ato voluntário de Maria, mas sim um fazer gênero regulado por normas discursivas que circulam pela performatividade. Há uma reprodução das normas performativas de gênero ao mesmo tempo que a participante desfaz, reproduzindo, descontruindo e colocando em xeque estas mesmas normas (Butler, 2003; West \& Zimmerman, 1987). Maria desfaz gênero e vai de encontro as marcas inscritas em seu corpo, desafiando discursos reiterados socialmente (Butler, 2003).

Por consequência da CPI, ela teve que andar acompanhada de uma figura masculina, seu irmão ou algum assessor homem, para que o impacto sobre sua vida diminuísse. Machado (1998) afirma que a mulher é vista como inferior ao homem na sociedade ocidental, e desafiar alguém ou algo do sistema vigente gera inúmeros problemas para o indivíduo. Maria desafiou um homem prefeito, visto por muitos como duas posições superiores a de Maria, o de homem como superior a mulher e de prefeito como superior ao vereador. Além disso, foi uma mulher presidindo uma CPI, algo nunca visto na cidade e região, subvertendo a ordem e sofrendo as consequências em função disto (Machado, 1998).

Os discursos de Maria evidenciaram que o seu estudo e os conhecimentos sobre os procedimentos e regimentos da Câmara foram fundamentais para o andamento do processo, foi esse o instrumento que a fez exercer poder durante a presidência. Assim, ela criou "essa identidade e essa posição com todo o povo e os colegas, uma identidade de que eu conheço, eu estudo” (Maria). Esse foi um fator fundamental durante a CPI e para que ela levasse a frente todo o processo.

Em relação à CPI, a gente foi muito difícil, até aqui na Câmara, no plenário, em discussões, nós já tivemos embates fortíssimos, e que muitos dos colegas não têm respeito nenhum em relação a se é mulher, né, inclusive assim, na própria discussão tentar intimidar com um tapa na mesa, ai eu já tive discurso também de ir lá na tribuna e meter o tapa na mesa, porque «olha, a força que você tem eu também tenho», a força física que você tem você tem aí, e o discurso eu tenho mais ainda que você. Então isso a gente vê demais, infelizmente ainda vê, e muitos assim, quando não consegue ir pelo argumento político, ai vai pra esse argumento de intimidação. Tanto que todas as sessões praticamente eu venho com uma pessoa, um homem, ou é marido, ou é o amigo, ou é meu irmão, porque infelizmente é isso, as vezes, agora não, mas já teve embates políticos que até a briga assim, de corredor que teoricamente na hora da gente sair a gente fica naquela da agressão até física, em relação à mulher como mais frágil, ele não vai no homem pra poder intimidar ele com a questão física, mas na mulher eles ainda vem com essa intimidação dentro do próprio plenário entendeu? Se é assim no dia-a-dia, imagine durante a CPI. (Maria) 
Os discursos de Maria demonstram que ela teve "que agir como homem diversas vezes". Ela bateu em mesas, falou de uma maneira rude, demonstrando que "agir desta forma era uma questão de sobrevivência como vereadora” (Charles, 2014). Butler (1999) discute que as performances são feitas de maneira estratégica, mas que esta estratégia não é elaborada pelo sujeito, o que está manifesto nos discursos da participante a ajudou dentro daquele espaço. As performances não são fixas de um ou outro gênero, e o fato de ser mulher ou homem não limita a pessoa ser compelida a ter performances de outro gênero (Butler, 2003). Maria, ao exercer essa performance, não estava fazendo de forma voluntarista, mas as relações de poder dentro da Câmara de Vereadores a compeliam atuar desta maneira (Butler, 1999).

Quando eu fui pegar os depoimentos dos envolvidos, muitos falavam assim: 'é mulher, é uma coisa que não vai da em nada, não é importante’. Menosprezaram o ato, achando que isso não ia dar em nada, e aí eles se enganaram não é?! Aí que eu via a cara de menosprezo de muitos, e quando eu vim pra poder prestar, e achando que não ia dar, e infelizmente deu [Um dos poucos momentos que Maria mais riu na entrevista]. (Maria)

Os discursos dos depoentes da CPI expressam práticas normativas, e todos eles foram homens. Ao falar frases como a expressa no fragmento anterior, estes indivíduos buscavam a identificação com os meios discursivos dessas normas regulatórias sujeitados pelos processos de subjetivação construídos por essa normatividade. Esta normatividade considerava Maria como inferior e como não pertencente àquele ambiente, fazendo com que eles acreditassem que não gerariam consequências maiores para eles (Butler, 1999, 2003). Entretanto, ocorreram diversas consequências judiciais para o prefeito, e os discursos de Maria manifestaram que isso foi algo consolador. Neles, foram expressos diversos sinais de alegria (risos) por conta da CPI ter ido à frente e gerado consequências, em que ela afirma que "valeu a pena ter sofrido cada menosprezo por parte do prefeito e sua turma... a justiça está demorando, mas não vai falhar”.

O prefeito acreditou que estava acima de Maria por ser vereadora e também por ser mulher, o que facilitaria a sua absolvição. O menosprezo com que ele se referia a ela através da mídia demonstrava isso. As identidades geram diferenças e também identidades vistas como superiores e inferiores na sociedade. A identidade da mulher, feminina, negra e homossexual são algumas que são tratadas como inferiores, excluindo parcelas da sociedade de diversos locais (Souza, Silva, \& Carrieri, 2012). Cabe ressaltar que Maria não se declara negra e nem homossexual, sendo a mesma oprimida pelo seu gênero. Na política institucional, os partidos discursam muito forte acerca do tratamento diferenciado entre gêneros, o que Maria demonstrou muitas vezes.

\section{Discursos nos partidos políticos}

"Os grupos e partidos políticos não valorizam a opinião das mulheres e pouco respeito têm para com elas" (Maria). Através dos discursos de Maria foi manifestado que, apesar dos 8 anos de mandato da sua mãe e os seus 8 anos, em nenhum momento ela acreditava que o partido a valorizou da maneira correta. Um discurso que ficou evidente foi a ida de Maria em eventos oposicionistas do seu partido no nível estadual, onde ela apoiou deputados que não pertenciam ao seu partido. A participante credita a não valorização dela por 
ser mulher e diz que qualquer homem que opine dentro do partido tem mais peso que as mulheres. Maria pertence a um partido considerado de direita, o que historicamente já traz algumas dificuldades, pois, segundo diversos estudos (Araújo, 2005; Wright, Azevedo, \& Santana, 2012), a própria ideologia partidária já exclui a mulher das discussões.

Os discursos de Maria e de seu partido manifestam que as mulheres não "tem nenhum poder de decisão” (Maria) ou até mesmo de influenciar as decisões partidárias, visto que apenas uma mulher pertence ao diretório. Um discurso que demonstra isto é que Maria, mesmo sendo vereadora de dois mandatos, e indo para o terceiro, não faz parte do diretório e nem é ouvida no partido, ao qual ela mesma atribui este fato por ser mulher. O diretório é responsável por dar o direcionamento político do partido e escolhe quem vai apoiar e qual as composições que o partido seguirá. Os partidos não têm colocado as mulheres em posições deliberativas e não têm dado espaço para elas (Araújo, 2005). Os aspectos visuais diferenciam indivíduos dentro dos partidos e fazem com que eles considerem alguns como sendo inferiores (Thanen \& Wallenberg, 2014). Maria afirmou que os partidos não implementam ações substantivas para incorporar as mulheres na política institucional, ficando apenas no campo da retórica.

Em muitos momentos, os discursos de Maria vão de encontro a falas suas, principalmente sobre as dificuldades das mulheres fazerem parte de grupos ou partidos políticos. Ela chega a afirmar que "ser mulher não é empecilho para entrar na política, o negócio é a mulher se disponibilizar a isso" (Maria), mas ela mesma enumera diversos problemas que seriam empecilhos. Maria diz que o que dificulta as mulheres entrarem na política é a falta de trabalho ou representação social delas. Na última eleição, em 2016, ela considerou um número muito bom de mulheres participantes em sua cidade, apesar disso, ela foi a única eleita ou reeleita, diminuindo a quantidade de 3 para apenas 1 vereadora.

Estamos precisando ainda de articulações em cima disso daí, inserir a mulher dentro do processo político, não só em eleição, mas com uma contex tualização que ela venha aparecer na comunidade, venha aparecer em trabalhos e fala 'não, são as mulheres, sou a mulher tal, que tá trabalhando em tal coisa', isso daí. (Maria)

Gênero é um aspecto político, e subverter com o sistema normativo hegemônico não é fácil. A própria construção dos indivíduos e as relações de gênero constituídas pelos discursos que circundam cada um desde a infância, a todo tempo busca coibir os sujeitos de subverterem com ele (Butler, 2003). A própria performatividade, ao circular regras discursivas construindo o que é uma mulher ou um homem, faz com que elas não busquem participar da vida política institucional, focando na vida doméstica (Butler, 2003).

Maria faz uma crítica ao sistema de cotas, pois para ela não há diferença se não inserir a mulher em todo o processo político, não somente no pleito eleitoral. Seus discursos manifestam a preocupação com o "histórico de vida, pois a maioria não tem militância em partidos” (Maria), o que acaba dificultando a eleição e a própria atuação da mulher na política institucional. Em alguns pontos da discussão, Maria traz a construção social como ferramenta fundamental para os indivíduos adentraram na política, e as cotas não auxiliam muito se não ocorrer uma mudança na construção social. Para ela, a mulher atuará mais politicamente quando sair da vida doméstica mais cedo e participar ativamente da vida social, assim como a abordagem trabalhada durante a pesquisa, em que o rompimento com esse modelo se dará na mudança da construção social de identidades de gênero (Foucault, 1985; Louro, 2003; Scott, 1995). 


\section{Considerações finais}

O objetivo deste trabalho foi entender como gênero é feito e desfeito por uma vereadora na sua atuação dentro da Câmara Municipal. Utilizou-se histórias vividas pela participante, o que possibilitou a compreensão das identidades de gênero performadas dentro da sua atuação na política institucional. Os discursos manifestaram que ela performava o masculino como uma estratégia de sobrevivência naquele espaço, fazendo com que ao mesmo tempo que subverte a performatividade, ela reiterava normas performativas de gênero que circulavam naquele ambiente. Ao fazer e desfazer a masculinidade e a feminilidade, Maria demonstrou que gênero não tem necessariamente a ver com questões anatômicas, mas algo que é feito e desfeito a todo instante, variando de acordo com os espaços.

Os discursos de Maria mostraram que as performances dos indivíduos nem sempre estão de acordo com a performatividade, e que as performances são feitas de forma contingenciada de acordo com o espaço no qual os indivíduos estão inseridos. O exemplo de Maria demonstrou que ela teve que fazer masculinidade para ser aceita na Câmara Municipal, e ao mesmo tempo que subvertia ela reproduzia as normas citacionais. Destarte, gênero se manifestou como uma ferramenta de poder que atua desde a constituição das identidades dos indivíduos até influenciando as performances individuais, que são coletivas. Gênero é um importante elemento para gerir a vida em sociedade, produzindo e reproduzindo categorias, bem como diversas obrigações sociais. Os discursos de Maria revelam que gênero se manifesta por atuações performáticas. Este trabalho se enquadra na crítica às perspectivas naturalistas e essencialistas de sexo, gênero e sexualidade, trazendo discussões de como os indivíduos estão sempre fazendo e desfazendo identidades no decorrer dos tempos e locais. Nesse caso, na política institucional.

Ademais, pesquisar sobre aspectos identitários nas organizações é um tema valioso para pesquisas organizacionais, principalmente utilizando a abordagem pós-estruturalista, pois tem sido pouco explorado no contexto brasileiro. A obra de Judith Butler e sua crítica as políticas identitárias devem ser levadas em consideração ao buscar melhorias dos espaços sociais. É importante afirmar que este artigo teve como delimitação a história de vida de uma vereadora no interior da Bahia. Como sugestão para futuros trabalhos, é significativo pesquisar outras identidades em casas legislativas, como, por exemplo: classe social, religião, sexualidade e raça; bem como pesquisar relações identitárias de gênero em outras casas legislativas. 


\section{Notas}

1 Derrida entende como citacionalidade a característica da linguagem e da escrita de ser repetível, de poder ser reproduzida sem a presença de quem escreveu e de um possível destinatário. (Reis \& Paraíso, 2014, p. 239)

2 Nome fictício da participante; escolhido por ser o nome mais comum do Brasil, segundo a ferramenta do IBGE disponível no site http://censo2010.ibge.gov.br/nomes.

\section{Referências}

Alvesson, M. \& Billing, Y. D. (2009). Understanding gender and organizations. London: Sage. Araújo, C. (2005). Partidos políticos e gênero: mediações nas rotas de ingresso das mulheres na representação política. Revista de Sociologia e Política, 24, 193-215.

Barbosa, C. F. (2008). Famílias - Pressupostos para a política local: sombra ou alicerce. Dissertação de Mestrado, Programa de Pós-graduação em Família na Sociedade Contemporânea, Universidade Católica de Salvador, BA.

Barros, V. D. \& Lopes, F. T. (2014). Considerações sobre a pesquisa em história de vida. In E. M. Souza (Org.), Metodologias e Analíticas Qualitativas em Pesquisa Organizacional: uma abordagem teórico-conceitual (pp. 41-64). Vitória: EDUFES.

Beauvoir, S. (2014). O segundo sexo. Rio de Janeiro: Nova Fronteira. (Original publicado em 1949)

Becker, H. S. (1999) Métodos de Pesquisa em Ciências Sociais. São Paulo: Hucitec.

Bruschini, C. \& Puppin, A. B. (2004). Trabalho de mulheres executivas no Brasil no final do século XX. Cadernos de pesquisa, 34(121), 105-138.

Bulos, U. L. (2001). Comissão parlamentar de inquérito: técnica e prática. São Paulo: Saraiva. Butler, J. (1988). Performative acts and gender constitution: An essay in phenomenology and feminist theory. Theatre journal, 40(4), 519-531.

Butler, J. (1999). Corpos que pesam: sobre os limites discursivos do "sexo". In G. Louro (Org.), O corpo educado: pedagogias da sexualidade (pp. 110-125). Belo Horizonte: Autêntica.

Butler, J. (2003). Problemas de gênero: feminismo e subversão da identidade. Rio de Janeiro: Civilização Brasileira.

Charles, N. (2014). Doing gender, practicing politics: Workplace cultures in local and devolved government. Gender, Work, \& Organization, 21(4), 368-380.

Cramer, L., Paula, A., \& Silva, Á. L. (2002). A inserção do feminino no universo masculino: representações da educação superior. Organizações \& Sociedade, 9(24), 25-37.

Czarniawska, B. (2006). Doing gender unto the other: fiction as a mode of studying gender discrimination in organizations. Gender, Work, \& Organization, 13(3), 234-253.

Davel, E. \& Alcadipani, R. (2003). Estudos críticos em administração: aprodução científica brasileira nos anos 1990. Revista de Administração de Empresas, 43(4), 72-85.

Foucault, M. (1985). Microfísica do poder (5 ${ }^{\mathrm{a}}$ ed.). Rio de Janeiro: Graal.

Foucault, M. (1995). O sujeito e o poder. In H. Dreyfus \& P. Rabinow (Eds.), Michel Foucault: uma trajetória filosófica: para além do estruturalismo e da hermenêutica. (pp. 231-249). Rio de Janeiro: Forense Universitária.

Foucault, M. (1999). A ordem do discurso (5 ed.). São Paulo: Loyola. 
Gill, R. (2002). Análise de discurso. In M. Bauer \& G. Gaskell (Eds.), Pesquisa qualitativa com texto, imagem e som (pp. 244-270). Petrópolis, RJ: Vozes.

Laqueur, T. (2001). Inventando o Sexo: corpo e gênero dos gregos a Freud. Rio de Janeiro: Relume Dumará.

Lloyd, M. (1999). Performativity, parody, politics. Theory, Culture, \& Society, 16(2), 195-213. Louro, G. L. (2003). Gênero, sexualidade e educação: uma perspectiva pós-estruturalista (6 ed.). Petrópolis, RJ: Vozes.

Machado, L. Z. (1998). Gênero, um novo paradigma. Cadernos Pagu, 11, 107-125.

Nogueira, C. (2001). A análise do discurso. In L. Almeida \& E. Fernandes (Eds.), Métodos e técnicas de avaliação: novos contributos para a pratica e investigação (pp. 15-48). Braga, PT: CEEP.

Phillips, M. \& Knowles, D. (2012). Performance and performativity: Undoing fictions of women business owners. Gender, Work, \& Organization, 19(4), 416-437.

Prasad, A. (2012). Beyond Analytical Dichotomies. Human Relations, 65(5), 567-595.

Queiroz, M. I. P. (1988). "Relatos orais: do 'indizível' ao 'dizível'”. In Von Simson, O. Moraes (Org.), Experimentos com histórias de vida (Itália-Brasil) (pp. 68-80). São Paulo: Vértice.

Reis, C. D. Á. \& Paraíso, M. A. (2014). Normas de gênero em um currículo escolar: a produção dicotômica de corpos e posições de sujeito meninos-alunos. Revista Estudos Feministas, 22(1), 237-256.

Schilt, K., \& Connell, C. (2007). Do work place gender transitions make gender trouble? Gender, Work, \&Organization, 14(6), 596-618.

Scott, J. (1995). Gênero: uma categoria útil de análise histórica. Educação \& Realidade, 20(2), 71-99.

Simões, F. I. W. \& Hashimoto, F. (2012). Mulher, mercado de trabalho e as configurações familiares do século XX. Revista Vozes dos Vales, 1, 1-25. Recuperado de http:// site.ufvjm.edu.br/revistamultidisciplinar/files/2011/09/Mulher-mercado-de-trabalho-e-asconfigura $\% \mathrm{C} 3 \% \mathrm{~A} 7 \% \mathrm{C} 3 \% \mathrm{~B} 5$ es-familiares-do-s $\% \mathrm{C} 3 \% \mathrm{~A} 9$ culo-XX_fatima.pdf

Souza, E. M. \& Carrieri, A. P. (2010). A analítica queer e seu rompimento com a concepção binária de gênero. Revista de Administração Mackenzie, 11(3), 46-70.

Souza, M. M. P. \& Carrieri, A. P. (2014). A análise de discurso em estudos organizacionais. In E. M. Souza (Org.), Metodologias e analíticas qualitativas: uma abordagem teórico-conceitual (pp. 13-40). Vitória: EDUFES.

Souza, E. M., Corvino, M. D. M. F., \& Lopes, B. C. (2013). Uma análise dos estudos sobre o feminino e as mulheres na área de administração: a produção científica brasileira entre 2000 a 2010. Organizações \& Sociedade, 20(67), 603-621.

Souza, E. M., Silva, A. R. L., \& Carrieri, A. P. (2012). Uma análise sobre as políticas de diversidade promovidas por bancos. Psicologia \& Sociedade, 24(2), 315-326.

Thanem, T. \& Wallenberg, L. (2016). Just doinggender? Transvestism and the Power of Underdoing Gender in Everyday Life and Work. Organization, 23(2), 250-271.

West, C. \& Zimmerman, D. H. (1987). Doinggender. Gender \& Society, 1(2), 125-151.

Westbrook, L. \& Schilt, K. (2014). Doing gender, determining gender: Transgender people, gender panics, and the maintenance of the sex/gender/sexuality system. Gender \& Society, 28(1), $32-57$.

Wright, S., Azevedo, E. L. \& Santana, J. (2012). As mulheres na disputa para o Senado no processo eleitoral de 2010. In J. E. D. Alves, C. R. Pinto, \& F. Jordão (Orgs.), Mulheres nas eleições de 2010 (pp. 257-281). São Paulo: ABCP/Secretaria de Políticas para as Mulheres. 


\section{ADLLER MOREIRA CHAVES}

\section{http://orcid.org/OOOO-0002-2612-6192}

É mestre em Administração pela Universidade Federal do Espírito Santo.

Endereço: Avenida Pedro Felipe Duarte, 4911 - São Sebastião, Guanambi, BA, CEP 46430-000

E-mail: adllerchaves@gmail.com

\section{ELOISIO MOULIN DE SOUZA}

http://orcid.org/0000-0002-0775-7757

É Pós-doutor em Administração pela University of Leicester School of Management (Reino Unido). Professor adjunto do curso de graduação e pós-graduação em Administração da Universidade Federal do Espírito Santo. Doutor em Psicologia pela Universidade Federal do Espírito Santo.

E-mail: eloisiomoulin@gmail.com

\begin{tabular}{|c|c|}
\hline Histórico & $\begin{array}{l}\text { Submissão em: 27/06/2017 } \\
\text { Revisão em: 20/08/2018 } \\
\text { Aceite em: 09/06/2019 }\end{array}$ \\
\hline Contribuição dos autores & $\begin{array}{l}\text { Concepção: AMC; EMS. } \\
\text { Coleta de dados: AMC. } \\
\text { Análise de dados: AMC. } \\
\text { Elaboração do manuscrito: AMC; EMS. } \\
\text { Crítico revisões de conteúdo intelectual importante: } \\
\text { AMC; EMS. } \\
\text { Final aprovação do manuscrito: EMS. }\end{array}$ \\
\hline Financiamento & $\begin{array}{l}\text { Durante o processo de coleta de dados, o pesquisador Ad- } \\
\text { ller Moreira Chaves era Bolsista da CAPES no programa } \\
\text { de Mestrado em Administração da Universidade Federal } \\
\text { do Espírito Santo (UFES). }\end{array}$ \\
\hline $\begin{array}{l}\text { Consentimento de uso de } \\
\text { imagem }\end{array}$ & Não se aplica \\
\hline $\begin{array}{l}\text { Aprovação, ética e } \\
\text { consentimento }\end{array}$ & $\begin{array}{l}\text { O estudo foi aprovado pelo Comitê de Ética e Pesquisa } \\
\text { (CEP) da UFES no mês de Outubro de } 2016 \text {, cujo } \\
\text { parecer é de número 1.775.770. A participante da pes- } \\
\text { quisa também assinou o Termo de Consentimento Livre } \\
\text { Esclarecido (TCLE), e foi devidamente explicado todos } \\
\text { os passos da pesquisa para a mesma, bem como concor- } \\
\text { dava com possíveis publicações futuras das informações } \\
\text { obtidas nos encontros. }\end{array}$ \\
\hline
\end{tabular}

